\title{
Comparison of Various Turbulence Models in Rotating Machinery Blade-to-Blade Passages
}

\author{
E.Y.K. $\mathrm{NG}^{\mathrm{a}, *}$ and S.T. TAN ${ }^{\mathrm{b}}$ \\ ${ }^{a}$ School of Mechanical and Production Engineering, Nanyang Technological University, \\ Nanyang Avenue, Singapore 639798; ' ${ }^{b}$ FerroTec Cooperation (S) Pte Ltd, \\ Kallang Basin Industry Estate, Kallang Ave., Singapore 639798
}

(Received 26 February 1999; In final form 22 March 1999)

\begin{abstract}
Numerical calculations on four blade passages are done using Q3D Navier-Stokes solver with a simple mixing length turbulence model and two more advanced transport-equation approaches. Mixing length is simple and cheap but crude, while more sophisticated transport approaches are more physical but more expensive. Predicted results using different turbulent models are discussed and compared with the laminar flow and well documented experimental results. Studies show that the model with more transport-equation predicts improved result as it includes the effects of upstream history into the velocity scale.
\end{abstract}

Keywords: Turbulent, CFD, Turbomachinery

\section{INTRODUCTION}

Most flow fields in fluid machinery passage are turbulent flow and it is one of the most complex problem in the area of computational fluid dynamic such as stall and surge phenomena in compressor system [14]. It is believed that the solution of timedependent three-dimensional full Navier-Stokes equations could describe turbulent flows completely. However, the computers such as workstations are not large and fast enough to solve the equations directly, for the required range of length and time scales, even for simple flows. Hence, it is practical of using some of the turbulent modelling to describe the turbulence motion instead of solving the full Navier-Stokes equation. Many publications recommended various types of turbulent models such as those by Baldwin-Lomax [1], Cebeci-Smith [2], Birch [3], Chien-Kim [4], Launder-Spalding [5], Myong-Kasagi [6], etc.

Depending on the number of transport-equation used, the turbulent models can be classified into zero-, one- and two-equation and higher-order models. Theoretically speaking, the more the number of transport equations involved, the more accurate the prediction is, as less assumptions are used. The aim of this paper is to evaluate the different types of turbulent models including zero-, one- and

*Corresponding author. Tel.: (01065)790-4455. Fax: (01065)791-1859. E-mail: mykng@ntu.edu.sg. 
two-equation models using a Q3D Navier-Stokes [7] and full energy equation unless otherwise stated, in one host code, with experimental data for axial turbomachinery application.

\section{TURBULENT MODELS}

\section{Baldwin-Lomax's Zero-Equation Model [1]}

In zero-equation model, the concept of mixing length is used. Dimensional analysis of variables shows that the turbulent viscosity, $\mu_{\mathrm{T}}$, divided by the density $\rho$ has the same dimensions as a length multiplied by a velocity. Hence momentum arguments can be used to show that $\mu_{\mathrm{T}}$ is a function of the flow density, a length scale in the flow and the local mean flow velocity. Typically, this relationship is given as

$$
\mu_{\mathrm{T}}=\rho l_{\mathrm{m}}^{2}\left(\frac{\partial \bar{U}}{\partial y}-\frac{\partial \bar{V}}{\partial x}\right) .
$$

For inner layer:

$$
l_{\mathrm{m}}=\kappa Y D,
$$

for outer layer:

$$
l_{\mathrm{m}}=Y_{\max } F_{\mathrm{KLEB}},
$$

where $\kappa$ is the von-Karman constant $(0.41), Y$ is the distance normal to nearest wall, $D$ is the van Driest damping factor with $D=1-\mathrm{e}^{-y^{+} / A^{+}}, y^{+}=$ $\left(Y \sqrt{\rho_{w} \tau_{w}}\right) / \mu_{w}, A^{+}=26, Y_{\max }$ is the value of $Y$ at the maximum value of the function $F_{w}(Y)$ which is $F_{w}(Y)=Y^{2}|w|,|w|$ is the magnitude of the vorticity given by $|w|=\partial u / \partial y-\partial v / \partial x, F_{\mathrm{KLEB}}$ is the Klebanoff intermittency factor:

$$
F_{\mathrm{KLEB}}=\left[1+5.5\left(\frac{C_{\mathrm{KLEB}} Y}{Y_{\max }}\right)^{6}\right]^{-1} .
$$

The turbulent viscosity can be written as:

Inner layer

$$
\mu_{\mathrm{T}}=\rho(\kappa Y D)^{2}[|w|]
$$

Outer layer

$$
\mu_{\mathrm{T}}=\rho C_{\mathrm{CL}} C_{\mathrm{CP}} F_{\mathrm{wake}} F_{\mathrm{KLEB}}
$$

with $C_{\mathrm{CL}}=0.0168, C_{\mathrm{CP}}=1.6, C_{\mathrm{KLEB}}=0.3$.

$$
F_{\text {wake }}=\min \left\{\begin{array}{l}
Y_{\max } F_{\max } \\
C_{\text {wake }} Y_{\max } u_{\text {dif }}^{2} / F_{\max },
\end{array}\right.
$$

where $Y_{\max }$ is the location of the maximum value, $F_{\max }$ of the function, $F_{w}=Y|w| D, u_{\mathrm{dif}}$ is the difference of the maximum and minimum of $u: u_{\mathrm{dif}}=$ $u_{\max }-u_{\min }, C_{\text {wake }}$ is the model constant, $\sim 0.25$.

\section{Birch's One-Equation Model [3]}

In one-equation model, the turbulent viscosity is related to the turbulent kinetic energy $k$ and is written as

$$
\mu_{\mathrm{T}}=C_{\mu} \rho F_{\mu} \sqrt{k} l_{\mathrm{m}} .
$$

The value of $k$ can be found from the transport equation

$$
\begin{aligned}
& \frac{\partial(\rho k)}{\partial t}+\frac{\partial(\rho u k)}{\partial x}+\frac{\partial(\rho v k)}{\partial y} \\
& =\frac{\partial}{\partial x}\left(\mu_{\mathrm{e}} \frac{\partial k}{\partial x}\right)+\frac{\partial}{\partial y}\left(\mu_{\mathrm{e}} \frac{\partial k}{\partial y}\right)+P_{\mu}-\rho_{\varepsilon},
\end{aligned}
$$

where $\varepsilon$ is the distribution of the dissipation rate of $k$,

$$
\begin{aligned}
\varepsilon & =\frac{\mu}{\rho} \frac{\overline{\partial u_{i}^{\prime}}}{\partial x_{j}} \frac{\partial u_{i}^{\prime}}{\partial x_{j}}, \\
P_{\mu} & =\tau_{x x} \frac{\partial u}{\partial x}+\tau_{x y} \frac{\partial u}{\partial y}+\tau_{y x} \frac{\partial v}{\partial x}+\tau_{y y} \frac{\partial v}{\partial y}, \\
\tau_{i j} & =-\overline{u_{i} u_{j}} .
\end{aligned}
$$

Energy dissipation equation is

$$
\varepsilon=\left[\frac{C_{\mathrm{D} 1}}{C_{\mu}} \mu_{\mathrm{T}}+C_{\mathrm{D} 2} \mu\right] \frac{k}{l_{\mathrm{m}}^{2}}
$$

with $\quad F_{\mu}=1-\exp \left(-B_{\mu} \operatorname{Re}_{k}\right), \quad \operatorname{Re}_{k}=(\rho \sqrt{k} L) / \mu$, $C_{\mathrm{D} 1}=0.164, C_{\mathrm{D} 2}=0.336, C_{\mu}=0.548, B_{\mu}=0.029$, 
$\kappa=0.41, l_{\mathrm{m}}$ is the mixing length scale which is exactly the same as that used in the BaldwinLomax's model.

\section{Standard Two-Equation Model [5]}

A standard $k-\varepsilon$ model developed by Launder and Spalding [5] is also coded. This is the most commonly used model for CFD calculations. Here

$$
\mu_{t}=\rho C_{\mu} \frac{k^{2}}{\varepsilon} .
$$

The partial differential equations used to find the values of $k$ and $\varepsilon$ are,

turbulence kinetic energy equation:

$$
\begin{aligned}
& \frac{\partial(\rho k)}{\partial t}+\frac{\partial(\rho u k)}{\partial x}+\frac{\partial(\rho v k)}{\partial y} \\
& =\frac{\partial}{\partial x}\left(\left(\mu+\frac{\mu_{t}}{\sigma_{k}}\right) \frac{\partial k}{\partial x}\right)+\frac{\partial}{\partial y}\left(\left(\mu+\frac{\mu_{t}}{\sigma_{k}}\right) \frac{\partial k}{\partial y}\right) \\
& \quad+G_{k}-\varepsilon
\end{aligned}
$$

and energy dissipation equation:

$$
\begin{aligned}
\frac{\partial(\rho \varepsilon)}{\partial t} & +\frac{\partial(\rho u \varepsilon)}{\partial x}+\frac{\partial(\rho v \varepsilon)}{\partial y} \\
= & \frac{\partial}{\partial x}\left(\left(\mu+\frac{\mu_{t}}{\sigma_{\varepsilon}}\right) \frac{\partial \varepsilon}{\partial x}\right)+\frac{\partial}{\partial y}\left(\left(\mu+\frac{\mu_{t}}{\sigma_{\varepsilon}}\right) \frac{\partial \varepsilon}{\partial y}\right) \\
& +\frac{\varepsilon}{k}\left(c_{1} G_{k}-c_{2} \varepsilon\right),
\end{aligned}
$$

where $\mu_{\mathrm{e}}=\mu+\mu_{t}$,

$$
\begin{aligned}
G_{k} & =\mu_{t}\left\{2\left[\left(\frac{\partial u}{\partial x}\right)^{2}+\left(\frac{\partial v}{\partial y}\right)^{2}\right]+\left(\frac{\partial u}{\partial y}+\frac{\partial v}{\partial x}\right)^{2}\right\}, \\
\sigma_{k} & =0.9, \sigma_{\varepsilon}=1.22, c_{1}=1.44, c_{2}=1.92 \\
C_{\mu} & =0.09 .
\end{aligned}
$$

\section{INITIAL AND BOUNDARY CONDITIONS}

\section{Inlet Conditions}

Values of $k$ and $\varepsilon$ are in general not known at the inlet but some reasonable assumptions can be made. The kinetic energy of turbulence is estimated as a percentage of the square of the average inlet velocity [8]:

$$
k_{\text {inlet }}=T_{\mathrm{i}} \bar{u}^{2}
$$

where $\bar{u}$ is the average inlet velocity, $T_{\mathrm{i}}$ is the turbulent intensity in percentage. Here, $T_{\mathrm{i}}$ is set to be $3 \%$ for compressors and $1 \%$ for turbine. The dissipation rate is calculated according to the equation

$$
\varepsilon_{\text {inlet }}=C_{\mu} \frac{k^{3 / 2}}{2 a r_{\mathrm{o}}},
$$

where $r_{\mathrm{o}}$ is the outer radius of the machine annular, $a=0.005, C_{\mu}=0.09$.

\section{Outlet Conditions}

For the fully developed flow:

$$
\begin{aligned}
& \left(\frac{\partial k}{\partial n}\right)_{\text {outlet }}=0, \\
& \left(\frac{\partial \varepsilon}{\partial n}\right)_{\text {outlet }}=0,
\end{aligned}
$$

where $n$ is the streamwise direction.

\section{Wall Function}

With the general $k-\varepsilon$ model and wall function, where the first computational grid point $\mathrm{P}$ close to the wall is in the turbulent sublayer, the following formulae are used:

$$
\begin{aligned}
y_{\mathrm{P}}^{+} & =\frac{\rho u_{\tau} y}{\mu}, \\
u_{\mathrm{P}}^{+} & =\frac{1}{\kappa} \ln \left(y_{\mathrm{P}}^{+}\right)+B, \\
u_{\tau} & =\sqrt{\frac{\tau_{\mathrm{w}}}{\rho}},
\end{aligned}
$$


where $\tau_{\mathrm{w}}$ is the wall shear stress

$$
\begin{aligned}
& v_{\mathrm{tP}}=\frac{y_{\mathrm{P}}^{+} v}{u_{\mathrm{P}}^{+}}, \quad y_{\mathrm{P}}>11.5, \\
& v_{\mathrm{tP}}=0, \quad y_{\mathrm{P}} \leq 11.5,
\end{aligned}
$$

$\kappa=0.4-0.42, B=5.0-5.5, C_{\mu}=0.09$,

$$
\begin{aligned}
& k_{\mathrm{P}}=\frac{u_{\tau}^{2}}{\sqrt{C_{\mu}}}, \\
& \varepsilon_{\mathrm{P}}=\frac{C_{\mu}^{3 / 4} k_{\mathrm{P}}^{3 / 2}}{\kappa y_{\mathrm{P}}} .
\end{aligned}
$$

\section{NUMERICAL RESULTS}

Four experiment test cases are used to validate the predicted results. The first is a transonic compressor rotor, experimental work has been done at the DFVLR [9] in Gottingen. The computational Hmesh and measured IsoMach contour plot at $45 \%$ span are shown in Figs. 1(a) and (b). This mesh density has been determined to represent' a good compromise between economy and grid independence. It is sufficient to resolve down to either linear sublayer (for $y^{+} \leq 11.25$ ) or log-law layer $\left(11.25<y^{+}<500\right)$ as the value of $y^{+}$for the grid next to the solid boundary is between 0.7 and 36 .

The IsoMach contours computed in Figs. 2-4 show that, on the suction side, strong acceleration just after the leading edge followed by a weak oblique shock. Different models produce slightly different results. The shock predicted by zeroequation model smears out into a wider number of grid. However, both the one- and two-equation models predict a sharper shock which are closer to the experimental result. All the models predict the shock at about $18-20 \%$ chord of the suction surface. For the same axial chord, the one-equation model produces the highest Mach number, the zeroequation model gives the lowest value while the two-equation model predicts an in between value that is closest to the experimental results. In brief,
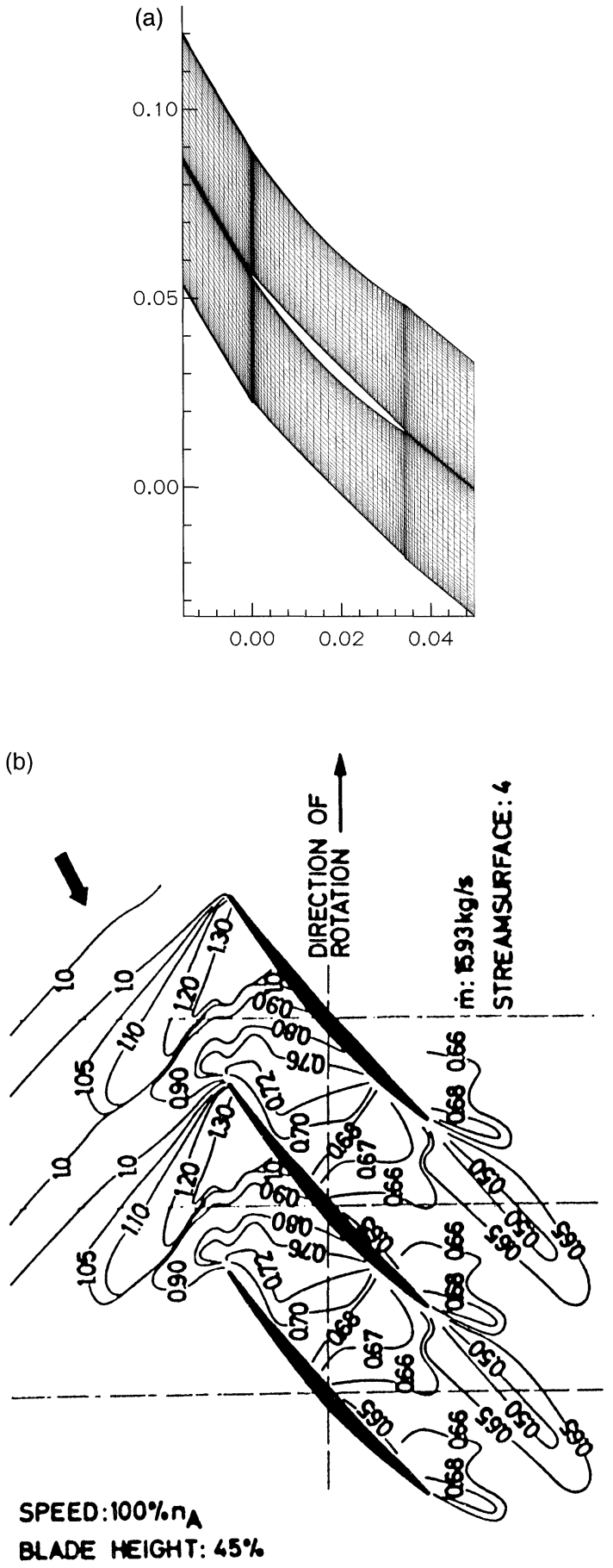

FIGURE 1 (a) Grid generated for transonic compressor rotor (mesh: $86 \times 45$ ); (b) Measured IsoMach contour at $45 \%$ span [9]. 


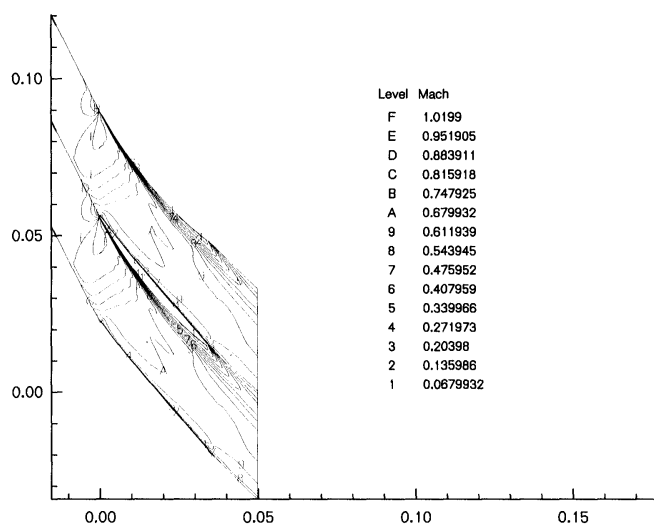

FIGURE 2 IsoMach contour at rotor mid-span using zeroequation model.

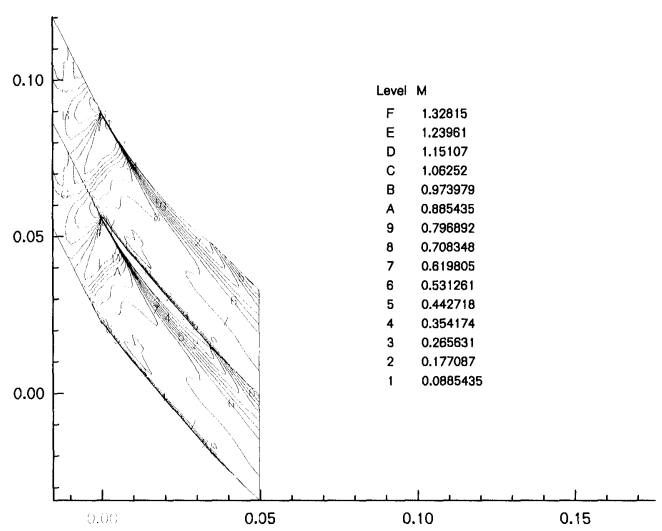

FIGURE 3 IsoMach contour at rotor mid-span using oneequation model.

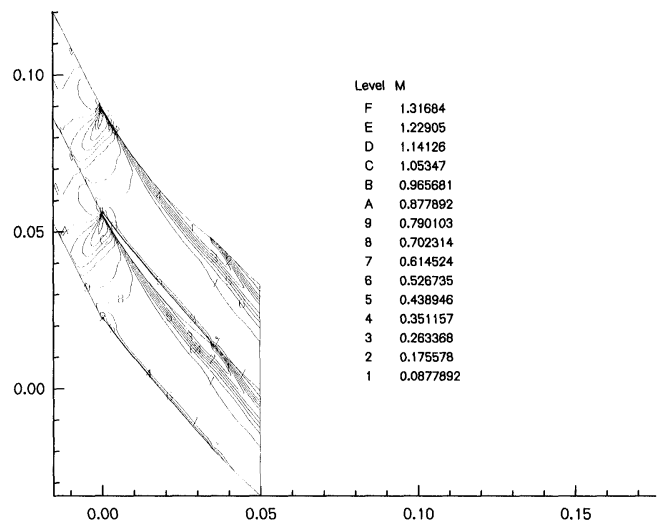

FIGURE 4 IsoMach contour at rotor mid-span using standard $k-\varepsilon$ model

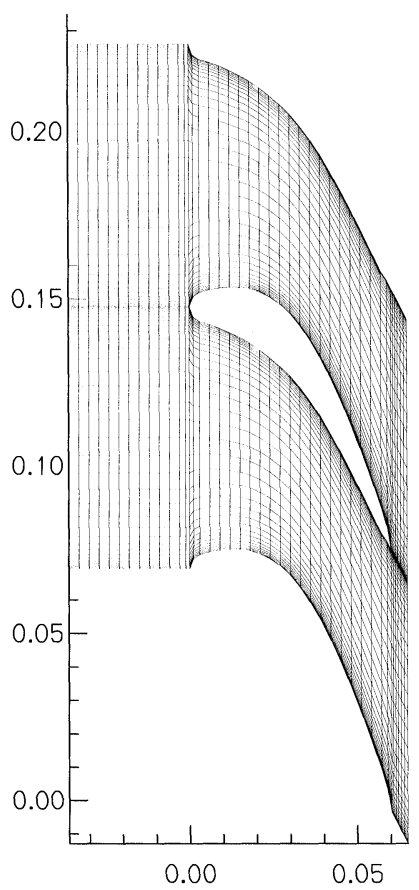

FIGURE 5 Grid generated for UTRC turbine stator (mesh: $42 \times 35)$

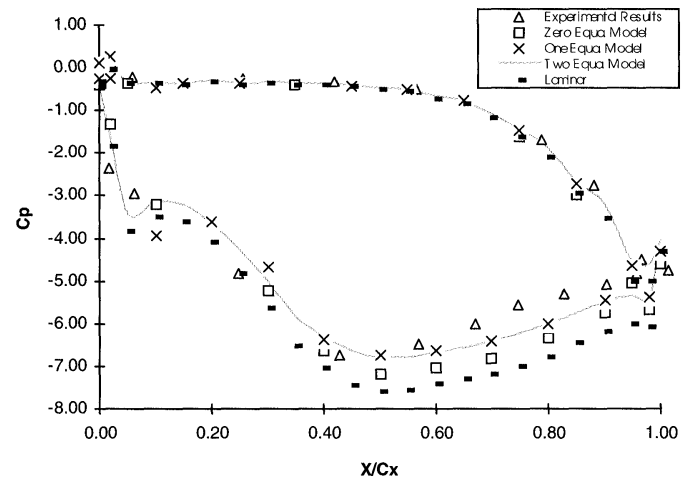

FIGURE 6 Blade pressure-coefficient prediction for UTRC turbine stator.

the predicted result by each model agrees qualitatively well against the experimental data.

The next test cases are the UTRC turbine blades. Experimental results [10] have been widely published. The mesh are shown in Figs. 5 and 7 for stator and rotor respectively.

The blade surface pressure-coefficient distributions $\left(C_{\mathrm{p}}=\left(P_{1}-P\right) / 0.5 \rho_{1} U_{1}^{2}\right)$ based on the inlet 
condition for UTRC turbine stator at the nominal operating point are compared in Fig. 6. It shows similarity between the predictions using each turbulence model. On the suction surface at same $X / C_{x}$ chord position, the zero-equation model predicts a lower value as compared to prediction by one- and two-equation models. However, on the pressure surface, all the models predicted similar $C_{\mathrm{p}}$ values and are very close to the experimental result. As the boundary layer at pressure surface is relatively thin and no significant separation occurs therefore all the turbulent models are able to predict more accurate results. Included also is the $C_{\mathrm{p}}$ prediction by laminar flow having similar shape to turbulent assumption but with a much lower $C_{\mathrm{p}}$ value at suction side.

Similarity, Fig. 8 compares the $C_{\mathrm{p}}$ distributions for turbine rotor. On both the blade surfaces at same $X / C_{x}$ position, zero-equation model predicts a lower value as compared to that by one- and twoequation models as well as the experimental result. The latter models are able to predict results which are very close to experimental result on pressure surface and second half of the suction surface.

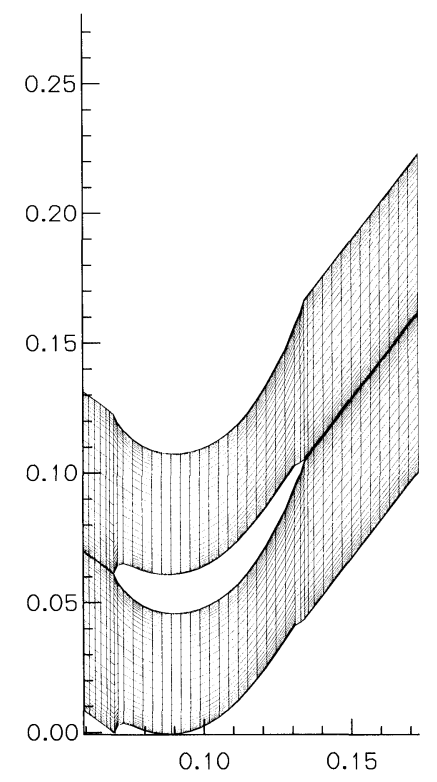

FIGURE 7 Grid generated for UTRC turbine rotor (mesh: $45 \times 35)$.
At the first $50 \%$ chord on the suction surface, the experimental result is lower than the prediction by one- or two-equation models. Same as in case of stator the $C_{\mathrm{p}}$ prediction by laminar flow has similar shape with that predicted by turbulent models but with a much lower $C_{\mathrm{p}}$ value at suction side. In the measurement, the flow has passed through the stator, which results in wake forming, flow distortion and non-uniformity at the rotor inlet in contrast to the computation. Large error at entrance of rotor was also found in the calculation by Lee et al. [11].

The final case is on $\mathrm{C} 4$ compressor blade where experimental data are available from [12] (Fig. 9).

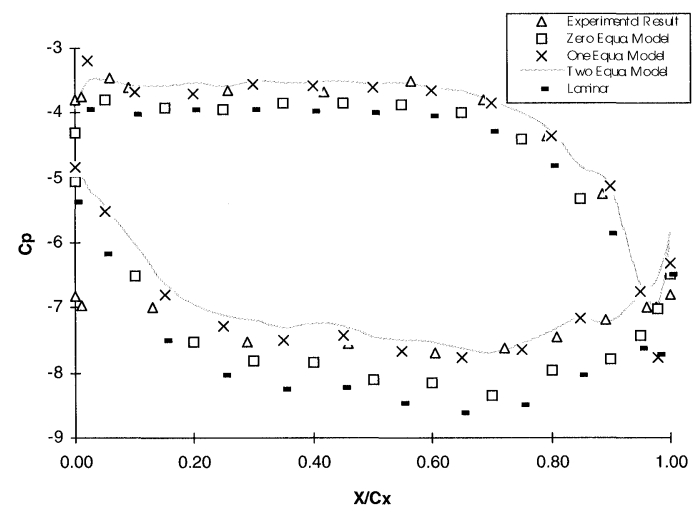

FIGURE 8 Blade pressure-coefficient prediction for UTRC turbine rotor

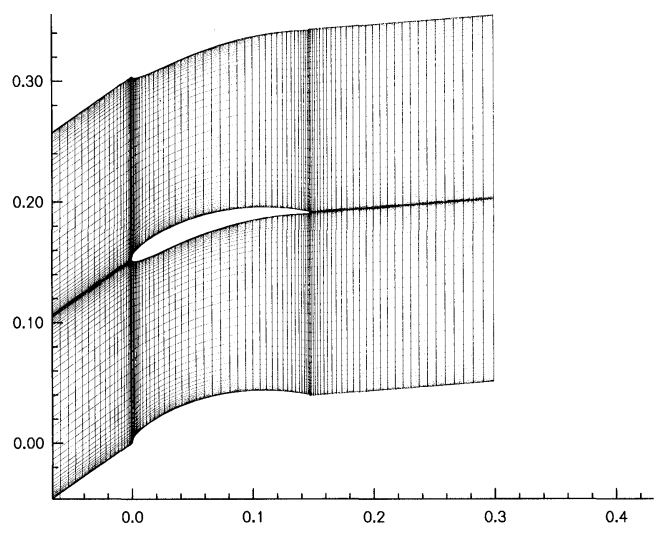

FIGURE 9 Grid generated for C4 compressor blade (mesh: $98 \times 45)$. 


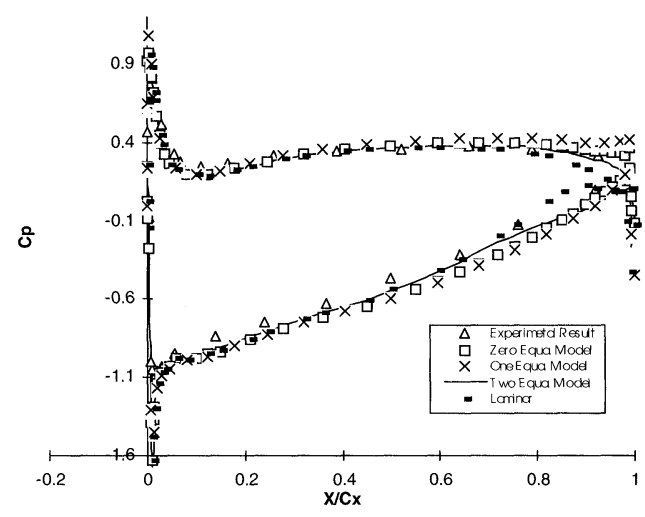

FIGURE 10 Blade pressure-coefficient prediction for $\mathrm{C} 4$ compressor blade.

Figure 10 compares blade surface pressurecoefficient distributions at the nominal operating point, showing similarity between the predictions using each turbulence model. On suction surface, at same position, it is shown that zero- and oneequation models predict similar values which are slightly lower than two-equation model as well as the experiment values. However, on pressure surface, zero- and one-equation models predictions agree well with measured data. Figure 10 also shows that the two-equation model agrees very well with the measurement at both blade surfaces. The prediction of $C_{\mathrm{p}}$ for laminar flow is similar to that predicted by turbulent models at most portion of the blade surfaces, except the region near trailing edge of the pressure side where laminar model predicts a small boundary separation bubble and hence lower pressure recovery as compared to turbulent models.

Local velocity profiles along $Y$-axis are plotted at $36 \%$ and $64 \%$ chords and compare with experimental result [12] as shown in Figs. 11 and 12 respectively. The $Y / Y_{\mathrm{e}}$ term is the nondimensionalized normal distance from the blade surface $Y$ with the boundary layer thickness $Y_{\mathrm{e}}$ (defined as the grid point with a speed less than $98 \%$ different compared to adjacent grid). The speed $U$ is non-dimensionalized with speed $U_{\mathrm{e}}$ which is the speed at $Y_{\mathrm{e}}$. At both chord-location,

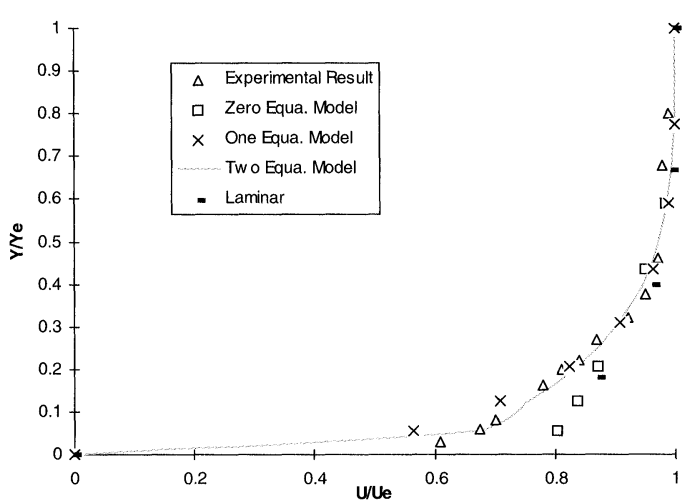

FIGURE 11 Non-dimensionalized $Y$-direction distance vs. velocity curve at $36 \%$ chord of suction side of $\mathrm{C} 4$ compressor blade.

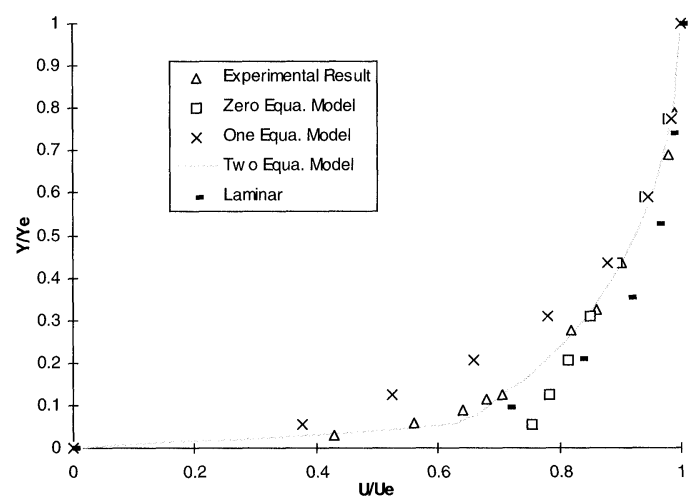

FIGURE 12 Non-dimensionalized $Y$-direction distance vs. velocity curve at $64 \%$ chord of suction side of $\mathrm{C} 4$ compressor blade.

the velocity profiles predicted by two-equation model agree very well with the experiment. At above $20 \%$ of boundary layer thickness, zero- and one-equation models predictions show good agreement with the experimental result. However, below $20 \%$ of boundary layer thickness, zeroequation model predicts lower value while the one-equation model gives a higher value. In brief, all the models are able to predict the growth of boundary layer and boundary separation. The laminar flow prediction is found to be quite similar to the zero-equation model. More details could be found in [13]. 


\section{CONCLUDING REMARKS}

The computed results were compared with measurement to validate the code and assess the quality of the numerical solution. The performance of the turbulence models to predict the flow through a blade passage depends on the number of transport equations used and on the inlet flow conditions. Another observation from the models used is their different separation behavior within the boundary layers.

It is shown that in most cases the two-equation model produces results which are closest to the experimental results followed by one-equation model. As the less simplification is made the closer to physics it will be.

Finally, for accurate simulations of fluid machinery, extension to three-dimension with transition and higher-order of turbulent model are needed.

\section{References}

[1] B. Baldwin and H. Lomax (1978). 'Thin layer approximation and algebraic model for separated turbulent flows', AIAA Paper, no. 78-257.

[2] T. Cebeci and A.M.O. Smith (1974). 'Analysis of turbulent boundary layers', Applied Mathematics and Mechanics, Vol. 15, Academic Press, New York.
[3] N.T. Birch (1987). 'Navier-Stokes predictions of transition loss and heat transfer in a turbine cascade', $A S M E$ 87-GT-22.

[4] Y.S. Chien and S.W. Kim (1987). 'Computation of turbulent flows using an extended $k-\varepsilon$ turbulence model', $N A S A$ CR-179204.

[5] B.E. Launder and D.B. Spalding (1974). 'The numerical computation of turbulent flow', Comp. Math. Appl. Mech. Eng., 3, 269-289.

[6] H.K. Myong and N. Kasagi (1990). 'A new approach to the improvement of the $k-\varepsilon$ turbulence model for bounded shear flows', JSME Int. J., Ser. B, 33, 63-72.

[7] E.Y.K. Ng and Y. Miao (1996). 'Viscous flow prediction of the single stage axial rotating machineries', CFD Journal, 403-420.

[8] H.K. Versteeg and W. Malalasekera (1995). An Introduction to Computational Fluid Dynamics, Longman Scientific \& Technical, Loughborough.

[9] L. Fottner (1990). 'Test cases for computation of internal flows in aero-engine components', NASA AGARD Advisory Report No: 275 (VI.4 Test Case E/CO-4 by Dunker, R.) pp. 245-285.

[10] R.P. Dring, H.D. Joslyn, L.W. Hardin and J.H. Wagner (1982). 'Turbine rotor and stator interaction', $A S M E$ Journal of Engineering for Power, 104, 729-742.

[11] Y.T. Lee, T.W. Bein, J. Feng and C.L. Merkle (1993). 'Unsteady rotor dynamics in cascade', ASME Journal of Turbomachinery, 115, 85-93.

[12] E.Y.K. Ng (1992). 'A high resolution coupled parabolic/ elliptic Navier-Stokes solver for turbomachinery flows', Ph.D. Thesis, University of Cambridge, UK.

[13] S.T. Tan (1998). Numerical investigation of viscous flow in rotating cavity with different turbulence models, M. Eng. Thesis, Nanyang Technological University, Singapore.

[14] E.Y.K. Ng, S.T. Tan and H.N. Lim (1997). 'Simulation of instability flow in compressor system', Proceedings of 8th Aerospace Technology Seminar, Singapore, pp. PR 4/1-4/7. 


\section{ait \\ ENERGY MATERIALS}

M A N E Y publishing

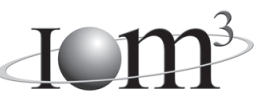

\section{Materials Science \& Engineering for Energy Systems}

Maney Publishing on behalf of the Institute of Materials, Minerals and Mining

The Institute of Materials, Minerals \& Mining

Economic and environmental factors are creating ever greater pressures for the efficient generation, transmission and use of energy. Materials developments are crucial to progress in all these areas: to innovation in design; to extending lifetime and maintenance intervals; and to successful operation in more demanding environments. Drawing together the broad community with interests in these areas, Energy Materials addresses materials needs in future energy generation, transmission, utilisation, conservation and storage. The journal covers thermal generation and gas turbines; renewable power (wind, wave, tidal, hydro, solar and geothermal); fuel cells (low and high temperature); materials issues relevant to biomass and biotechnology; nuclear power generation (fission and fusion); hydrogen generation and storage in the context of the 'hydrogen economy'; and the transmission and storage of the energy produced.

As well as publishing high-quality peer-reviewed research, Energy Materials promotes discussion of issues common to all sectors, through commissioned reviews and commentaries. The journal includes coverage of energy economics and policy, and broader social issues, since the political and legislative context influence research and investment decisions.

\section{CALL FOR PAPERS}

Contributions to the journal should be submitted online at http://ema.edmgr.com

To view the Notes for Contributors please visit: www.maney.co.uk/journals/notes/ema

Upon publication in 2006, this journal will be available via the Ingenta Connect journals service. To view free sample content online visit: www.ingentaconnect.com/content/maney

For further information please contact:

Maney Publishing UK

Tel: +44 (0)113 2497481 Fax: +44 (0)1132486983 Email: subscriptions@maney.co.uk

or

Maney Publishing North America

Tel (toll free): 8662975154 Fax: 6173546875 Email: maney@maneyusa.com

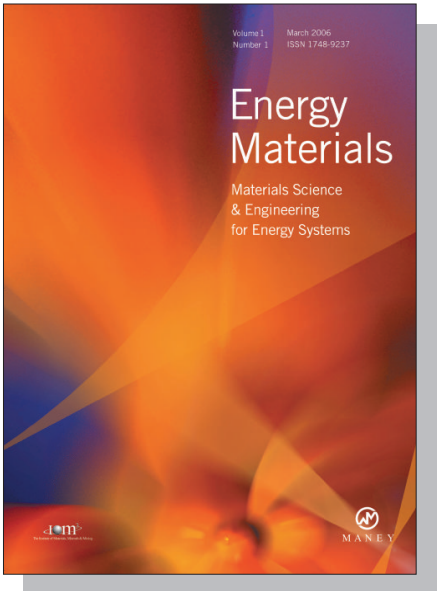

EDITORS

Dr Fujio Abe

NIMS, Japan

Dr John Hald, IPL-MPT, Technical University of Denmark, Denmark

Dr R Viswanathan, EPRI, USA

\section{SUBSCRIPTION INFORMATION}

Volume 1 (2006), 4 issues per year

Print ISSN: 1748-9237 Online ISSN: 1748-9245

Individual rate: $£ 76.00 / U S \$ 141.00$

Institutional rate: $£ 235.00 /$ US $\$ 435.00$

Online-only institutional rate: $£ 199.00 / U S \$ 367.00$

For special $\mathrm{IOM}^{3}$ member rates please email

subscriptions@maney.co.uk

\section{For further information or to subscribe online please visit www.maney.co.uk}



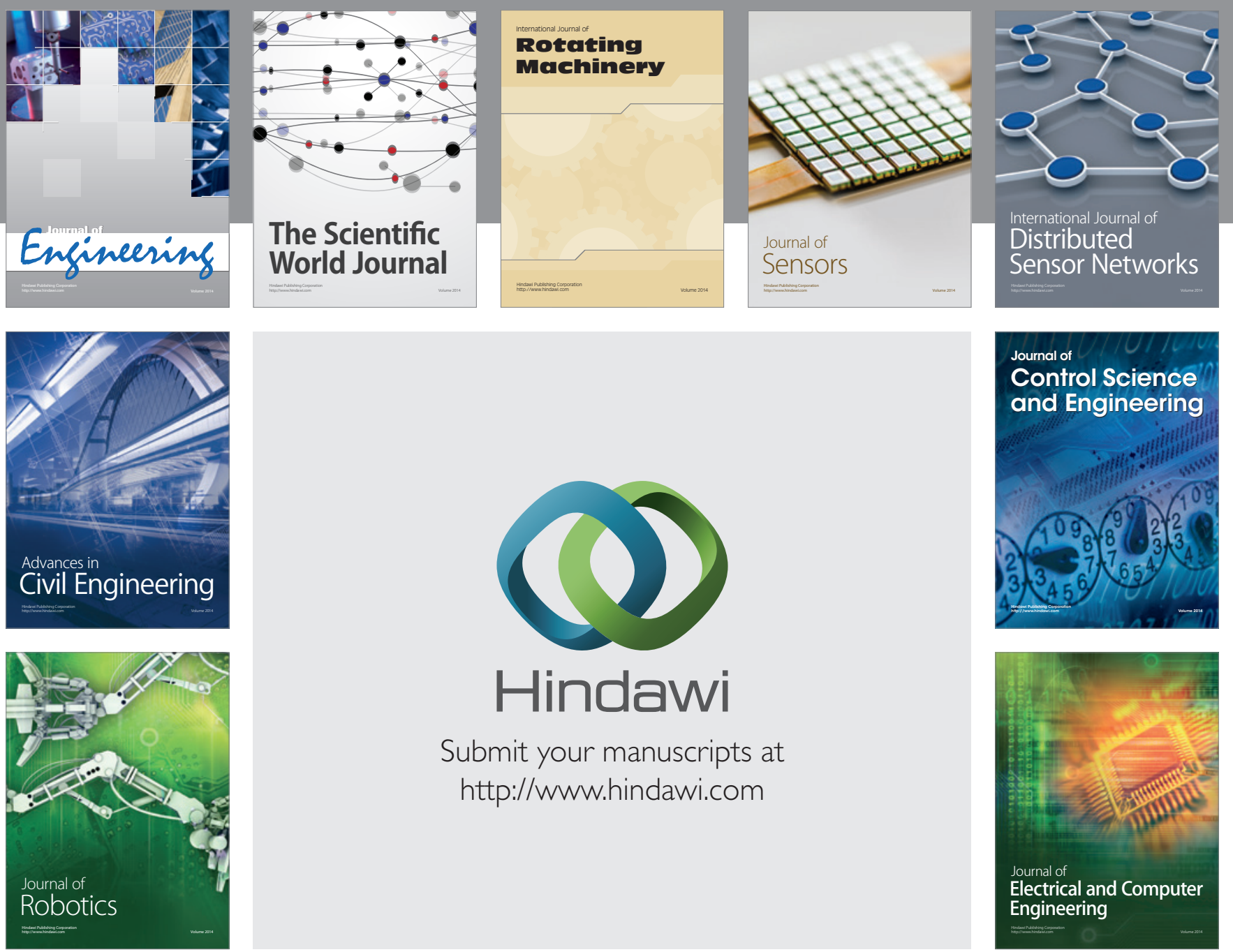

Submit your manuscripts at

http://www.hindawi.com
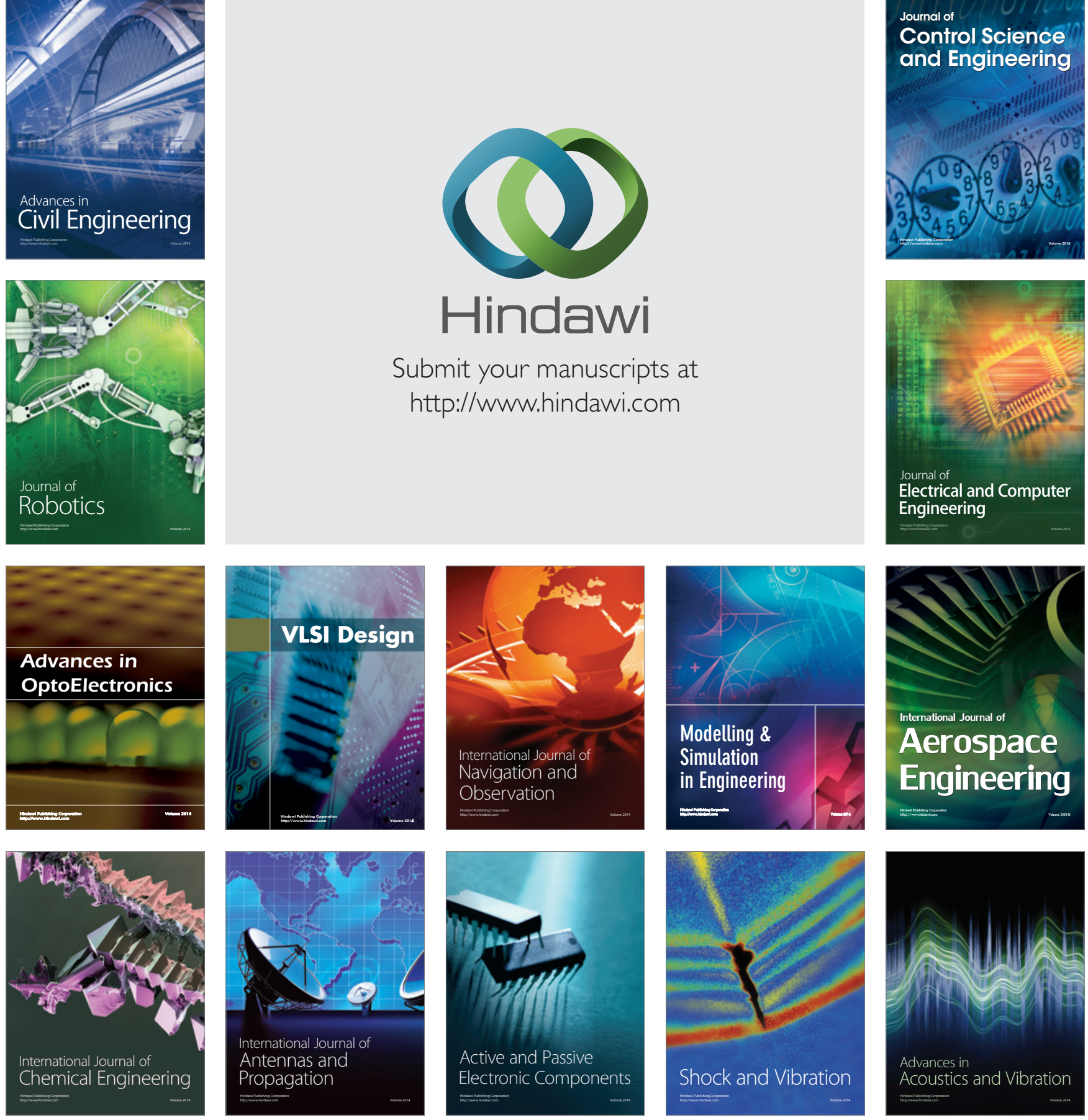